\title{
Oscillatory carbonylation of phenylacetylene in the absence of externally supplied oxidant
}

\author{
Lynn Donlon • Julie Parker • Katarina Novakovic
}

Received: 20 December 2013/ Accepted: 3 February 2014/Published online: 19 February 2014

(C) The Author(s) 2014. This article is published with open access at Springerlink.com

\begin{abstract}
The palladium-catalyzed oxidative carbonylation of phenylacetylene (PCPOC reaction) is known to exhibit autonomous oscillations in a variety of parameters including $\mathrm{pH}$, redox potential and heat of reaction. Previous studies report that external addition of both an oxidizing agent and water is required to allow production/ consumption of $\mathrm{H}^{+}$in an oscillatory fashion. In this work we show that solutions of $\mathrm{PdI}_{2} /$ KI dried over $3 \AA$ molecular sieves can catalyze phenylacetylene carbonylation in the absence of an external oxidizing agent. Oscillations are readily achieved in this considerably simplified PCPOC system. Palladium-catalyzed carbonylation of methanol generates $\mathrm{HI}$ as a by-product, which can react with excess $\mathrm{KI}$ and methanol producing methyl iodide and water in situ. Methyl iodide can also undergo decomposition, generating iodine as an internally formed oxidizing agent, which accounts for recorded catalyst regeneration. Oscillations are observed in the $\mathrm{pH}$ range 1.5-3.5 commencing, at the earliest, $70 \mathrm{~min}$ after introduction of phenylacetylene. Oscillations vary in period between 1 and $3.5 \mathrm{~h}$ and last for several days. The onset of oscillations may be delayed via portion-wise addition of the phenylacetylene substrate.
\end{abstract}

Keywords Oscillatory reaction $\cdot \mathrm{pH}$ oscillator - Carbonylation reaction · Palladium catalysis

\section{Introduction}

In recent years, chemical systems that exhibit rhythmical oscillations have progressed from fascinating, but obscure phenomena to a valuable driving force for responsive and

L. Donlon · J. Parker · K. Novakovic $(\bowtie)$

Chemical Engineering and Advanced Materials,

Newcastle University, Newcastle-Upon-Tyne NE1 7RU, UK

e-mail: katarina.novakovic@ncl.ac.uk 
self-actuating materials $[1,2]$. As our understanding of the mechanisms underlying these complex systems continues to develop, so does the potential to exploit key characteristics such as autonomous changes in $\mathrm{pH}$. A wide variety of systems are now known to act as chemical oscillators including variations of the well-known BelousovZhabotinsky and Briggs-Rauscher reactions [3]. $\mathrm{pH}$ oscillators, defined as systems in which changes in $\mathrm{H}^{+}$concentration are the driving force behind oscillatory behavior [4], rely on autocatalytic generation of $\mathrm{H}^{+}$and corresponding reactions that consume $\mathrm{H}^{+}$. Such reactions usually involve the oxidation of organic substrates, (e.g. malonic acid), by a variety of oxidants including $\mathrm{O}_{2}, \mathrm{H}_{2} \mathrm{O}_{2}, \mathrm{BrO}_{3}{ }^{-}$and $\mathrm{IO}_{3}{ }^{-}$, forming $\mathrm{CO}_{2}$, water etc. Each process is catalyzed by transition metal ions and complexes such as $\mathrm{Ce}(\mathrm{IV}) / \mathrm{Ce}(\mathrm{III})$, $\mathrm{Ru}(\mathrm{III}) / \mathrm{Ru}(\mathrm{II}), \mathrm{Fe}(\mathrm{III}) / \mathrm{Fe}$ (II) or $\mathrm{Mn}$ (III)/(Mn(II) [3].

An alternative class of chemical oscillator is that in which complex organic molecules are synthesized from simple building blocks such as carbon monoxide, alcohols and acetylenes. Mechanistic pathways are present that both produce and consume $\mathrm{H}^{+}$leading to periodic oscillations in $\mathrm{pH}$. One such example is the palladium-catalyzed oxidative carbonylation of acetylenes to esters and carboxylic acids $[5,6]$. The oxidative carbonylation of phenylacetylene (PCPOC reaction) using $\mathrm{PdI}_{2}, \mathrm{KI}, \mathrm{O}_{2}$ and $\mathrm{NaOAc}$ in methanol was shown to display oscillations in $\mathrm{pH}$, redox potential and the rate of consumption of a $\mathrm{CO}-\mathrm{O}_{2}$ gas mixture $[6,7]$. Substrates such as methylacetylene and 2-methyl-3-butyn-2-ol display similar oscillatory behavior [8]. More recent studies of the PCPOC reaction using power compensation calorimetry confirm synchronized oscillations in reaction exothermicity and $\mathrm{pH}$. A 'staircase' of exothermic pulses of up to $600 \mathrm{~J}$ per oscillation coincides with corresponding falls in $\mathrm{pH}$ [9].

Interestingly, the oxidative carbonylation of phenylacetylene has been shown to act in both oscillatory and non-oscillatory modes with significant differences observed in both conversion and product selectivity $[10,11]$. In the case of nonoscillatory oxidative carbonylation, product formation is unhindered from the start of the reaction and results in a mixture of products including: E-3-phenylacrylic acid methyl ester, 1; 2-phenylacrylic acid methyl ester, 2; Z-2-phenylbut-2-enedioic acid dimethyl ester, 3; E-3-phenylacrylic acid methyl ester, 4; 3-phenyl-5H-furan-2-one, 5; 3-phenylfuran-2,5-dione, 6 and Z-2-phenyl-2-butenedioic acid, 7, Fig. 1 [10]. When operating in an oscillatory regime, product formation is suppressed pending the onset of oscillations, upon which 3 is formed with greater than $75 \%$ selectivity. Minor products are 4, 6, 7 and 5,5-dimethoxy-3-phenyl-furan-2(5)-one, 8 [11].

The process of oxidative carbonylation in a non-oscillatory regime has been studied in detail by Gabriele et al. [13]. In order for the reaction to be catalytic rather than stoichiometric, an external oxidant (such as quinones, copper(II), oxygen or a combination of these) is required to drive reoxidation of the metal center. Traces of water may limit catalytic activity due in part to competitive oxidation of $\mathrm{CO}$ to $\mathrm{CO}_{2}[13,14]$. Oxidation of $\mathrm{CO}$ can proceed stoichiometrically, generating $\mathrm{HI}$ as a by-product, or catalytically, in the presence of an oxidant such as $\mathrm{O}_{2}$, reducing both selectivity and conversion [13].

Water has been reported to form in a 1:1 ratio to products in the oscillatory carbonylation of phenylacetylene. However, the authors also add water prior to commencing the reaction ( $\sim 0.2 \mathrm{M}$ initial concentration) as it is believed to be 


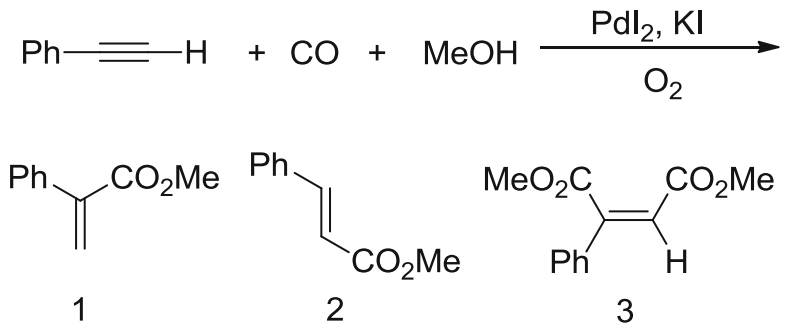

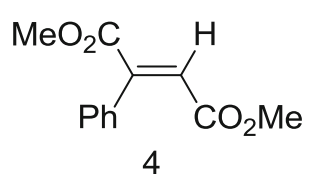<smiles>O=C(O)/C=C(\C(=O)O)c1ccccc1</smiles><smiles>O=C1OCC=C1c1ccccc1</smiles>

5<smiles>O=C1C=C(c2ccccc2)C(=O)O1</smiles>

6<smiles>COC1(OC)C=C(c2ccccc2)C(=O)O1</smiles>

Fig. 1 Reaction products observed during the palladium-catalyzed oxidative carbonylation of phenylacetylene. Operation in a non-oscillatory mode yields mixtures of $1,2,3,4,5,6$ and 7. 6/7 are not readily distinguished using GC-MS [12]. In contrast, operation in an oscillatory regime yields $\mathbf{3}$ as the major product with $4,6 / 7$ and $\mathbf{8}$ observed in smaller quantities

crucial in the formation of an intermediate HPdI species which contributes to oscillatory behavior [6]. The formation of diesters in an oscillatory regime is reported to be catalyzed by $\mathrm{Pd}(\mathrm{I})$-based species (e.g. $\operatorname{Pd}_{2} \mathrm{I}_{2}$ or $\mathrm{Pd}_{2} \mathrm{I}_{4}(\mathrm{CO})_{2}^{2-}$ ), even in the presence of oxygen, with $\mathrm{Pd}_{2} \mathrm{I}_{2}$ formed via reaction of $\mathrm{HPdI}$ with either $\mathrm{PdI}_{2}$ or $\mathrm{O}_{2}$ (generating $\mathrm{HI}$ or $\mathrm{H}_{2} \mathrm{O}_{2}$ as by-products, respectively) [14]. The presence of an external oxidizing agent was also understood to be necessary for both oscillatory and non-oscillatory carbonylation processes to proceed catalytically [14].

In this work we demonstrate that solutions of $\mathrm{PdI}_{2} / \mathrm{KI}$ in methanol, dried over $3 \AA$ molecular sieves, can catalyze the oxidative carbonylation of phenylacetylene in an oscillatory mode. In addition, it is revealed that this oscillatory system does not require an external oxidizing agent in order for catalyst recycling to occur. Furthermore, oscillatory behavior is recorded using considerably lower concentrations of both $\mathrm{PdI}_{2}$ (approximately fivefold) and phenylacetylene (approximately 40-80-fold) compared to those reported previously [9-11, 17]. As a result, the transparency of the reaction solution is significantly increased.

\section{Experimental}

Materials and methods

All materials were purchased from Sigma Aldrich and used without further purification unless otherwise stated. Catalyst solutions were prepared by dissolving palladium(II) iodide $(401 \mathrm{mg}, 1.1 \mathrm{mmol})$ and potassium iodide (24.93 $\mathrm{g}$, 
$150 \mathrm{mmol})$ in HPLC grade methanol $(300 \mathrm{~mL})$. The mixture was stirred at ambient temperature for $48 \mathrm{~h}$ and the resulting solution filtered through a $0.2 \mu \mathrm{m}$ Millipore membrane filter to remove residual $\mathrm{PdI}_{2}(57 \mathrm{mg})$. The concentration of the resulting catalyst solution was then adjusted using additional methanol and the solution dried (minimum of $24 \mathrm{~h}$ ) and stored over $3 \AA$ molecular sieves prior to use. Catalyst solutions were then either used neat or diluted to working concentrations using predried HPLC grade methanol (stored over $3 \AA$ molecular sieves for a minimum of $24 \mathrm{~h}$ prior to use). Catalyst solutions stored over molecular sieves are referred to as pre-dried rather than dry within the text as water concentrations are very low, but non-zero [15]. Previous studies report vastly different behavior when comparing HPLC grade solutions to those stored over molecular sieves [12].

All experiments were conducted at room temperature with no external temperature control. However, the temperature was recorded during each reaction. For simplicity, $\mathrm{pH}$ values were measured using an aqueous $\mathrm{pH}$ electrode calibrated using aqueous buffers ( $\mathrm{pH} \mathrm{2,7}$ and 10). Due to the non-aqueous nature of the reaction media (methanol) and differing junction potentials during calibration and sample measurement, absolute values of hydrogen ion activities are not obtained. Instead an approximation is acquired using adjusted $\mathrm{pH}$ values $\left(\mathrm{pH}_{\mathrm{adj}}\right)$, which provides a useful comparison of relative acidities. In methanol, $\mathrm{pH}_{\mathrm{adj}}$ is approximated by adding $2.3 \mathrm{pH}$ units to the measured value of $\mathrm{pH}\left(\mathrm{pH}_{\mathrm{app}}\right)$ and hydrogen ion concentrations subsequently estimated using $\left.10^{-(\mathrm{pHapp}}+2.3\right)$ [16]. The formation of water during the PCPOC reaction could in theory change the solvent composition and affect $\mathrm{pK}_{\mathrm{a}}$ values. However, the amounts expected to be produced are well below the $1 \% \mathrm{v} / \mathrm{v}$ level suggested to have an effect and for this reason are discounted [16].

\section{Sampling procedures}

Samples were filtered through silica to remove any solid palladium species and transferred to GC vials. The solutions were then analyzed using GC-MS without further dilution. Analysis of samples was carried out using a Varian Saturn 2000 GC-MS fitted with a Varian VF-5 ms column. The same GC method was employed for all samples: injector temperature $150{ }^{\circ} \mathrm{C}$, initial oven temperature $100{ }^{\circ} \mathrm{C}$, followed by five successive ramps $\left(1 \mathrm{~min}\right.$ at $20{ }^{\circ} \mathrm{C} \min ^{-1}$ then hold for $5 \mathrm{~min}$ ) up to $195{ }^{\circ} \mathrm{C}$, which was held for $8 \mathrm{~min}$.

\section{Oscillatory runs}

Two semi-batch runs are reported as examples of the palladium-catalyzed carbonylation of phenylacetylene operating in an oscillatory mode. Pre-dried solutions of $\mathrm{PdI}_{2} / \mathrm{KI}$ were used as described in Table 1 and a stable baseline $\mathrm{pH}$ value was obtained for approximately $5 \mathrm{~min}$ prior to purging with $\mathrm{CO}$. Exact baseline values, whilst dependent upon $\left[\mathrm{PdI}_{2}\right]$, were stable within any given experiment. Phenylacetylene was then added in aliquots as described in Table 1. CO purging was maintained throughout the course of the reaction resulting in a positive pressure of $\mathrm{CO}$ in the closed but not hermetically sealed reaction vessels. 
Table 1 Reaction conditions for oscillatory PCPOC runs

\begin{tabular}{llllllll}
\hline Run & $\begin{array}{l}\text { Reaction } \\
\mathrm{T}\left({ }^{\circ} \mathrm{C}\right)\end{array}$ & $\begin{array}{l}\text { Reaction } \\
\text { volume }(\mathrm{mL})\end{array}$ & $\begin{array}{l}{\left[\mathrm{PdI}_{2}\right]} \\
\left(\times 10^{-4} \mathrm{M}\right)\end{array}$ & $\begin{array}{l}{[\mathrm{KI}]} \\
(\mathrm{M})\end{array}$ & $\begin{array}{l}\mathrm{CO} \text { flow rate } \\
\left.(\mathrm{mL} \mathrm{min})^{-1}\right)\end{array}$ & $\begin{array}{l}\text { Volume PhAc } \\
(\mu \mathrm{L})\end{array}$ & $\begin{array}{l}{[\mathrm{PhAc}]_{\text {total }}} \\
(\mathrm{mM})\end{array}$ \\
\hline 1 & $16 \pm 2$ & 17 & 5.4 & 0.08 & 10 & $3(1+1+1)$ & $1.6^{\mathrm{a}}$ \\
$2^{\mathrm{b}}$ & $22 \pm 2$ & 90 & 6.4 & 0.105 & 15 & 29.5 & 3.0 \\
\hline
\end{tabular}

${ }^{\text {a }}$ Phenylacetylene $(P h A c)$ added in 3 equal portions

b $[$ Naphthalene] (internal standard) $=0.02 \mathrm{M}$

Run 1 was conducted on a small scale ( $17 \mathrm{~mL}$ of pre-dried $\mathrm{PdI}_{2} / \mathrm{KI}$ solution, Table 1 ) in a $25 \mathrm{~mL}$ sample vial and was monitored using a HEL MicroNOTE system. After determination of a stable baseline $\mathrm{pH}$, the $\mathrm{PdI}_{2} / \mathrm{KI}$ solution was purged with $\mathrm{CO}$

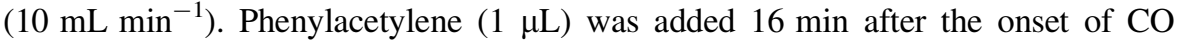
purging, with two further $1 \mu \mathrm{L}$ aliquots of phenylacetylene added 62 and 180 min later, giving a total concentration of phenylacetylene of $1.6 \mathrm{mM}$, Table 1.

Run 2 was conducted on a larger scale ( $90 \mathrm{~mL}$ of pre-dried $\mathrm{KI} / \mathrm{PdI}_{2}$ solution) in order to allow for sampling. The reaction was carried out in a jacketed glass vessel with ports to accommodate $\mathrm{pH}$ and temperature probes, $\mathrm{CO}$ inlet and allow easy removal of samples. A new batch of catalyst solution was prepared (concentration as described in Table 1) and the experiment was monitored using a different $\mathrm{pH}$ probe and different equipment (HEL Simular). Due to the limitations of the mass flow controller, a higher $\mathrm{CO}$ flow rate of $15 \mathrm{~mL} \mathrm{~min}^{-1}$ was used. Prior to commencement of $\mathrm{pH}$ monitoring, naphthalene $(231 \mathrm{mg}, 1.8 \mathrm{mmol}, 0.02 \mathrm{M})$ was dissolved in the catalyst $\left(\mathrm{PdI}_{2} / \mathrm{KI}\right)$ solution to act as an internal standard. After determining the baseline $\mathrm{pH}$, the $\mathrm{PdI}_{2} / \mathrm{KI} /$ naphthalene solution was purged with $\mathrm{CO}$ $(15 \mathrm{~min})$ and treated with phenylacetylene $(29.5 \mu \mathrm{L})$, giving a total phenylacetylene concentration of $3 \mathrm{mM}$. CO purging was maintained throughout the experiment. Compared to Run 1, higher concentrations of $\mathrm{PdI}_{2}$, $\mathrm{KI}$ and phenylacetylene were used with phenylacetylene added as a single aliquot.

\section{Initial $\mathrm{pH}$ drop upon $\mathrm{CO}$ purging}

Studies relating catalyst concentration and the initial $\mathrm{pH}$ drop upon $\mathrm{CO}$ purging of pre-dried catalyst solution were carried out using HEL MicroNOTE connected to a $\mathrm{pH}$ electrode and Pt100 temperature probe. In each case, the pH electrode was immersed in the catalyst solution and a baseline $\mathrm{pH}$ reading obtained over a $5 \mathrm{~min}$ period. Each solution was then purged for $15 \mathrm{~min}$ with $\mathrm{CO}\left(10 \mathrm{~mL} \mathrm{~min}{ }^{-1}\right)$ and the $\mathrm{pH}$ monitored.

Formation of methyl iodide

In order to investigate the formation of methyl iodide as a function of time, the $\mathrm{pH}$ of a pre-dried solution of $\mathrm{PdI}_{2} / \mathrm{KI}\left(25 \mathrm{~mL}, 2.68 \mathrm{mM} \mathrm{PdI}_{2}\right)$, containing naphthalene $(0.002 \mathrm{M})$ as an internal standard, was monitored for 5 min using HEL MicroNOTE before purging with $\mathrm{CO}\left(10 \mathrm{~mL} \mathrm{~min}{ }^{-1}\right)$. Samples were taken at various intervals 
over a $5 \mathrm{~h}$ period, filtered and analyzed using GC-MS. Molecular sieves $(3 \AA$, $350 \mathrm{mg}$ ) were added $259 \mathrm{~min}$ into the experiment to assess the response to the removal of water.

\section{Results and discussion}

The oscillatory $\mathrm{pH}$ behavior recorded in Run 1 is given in Fig. 2. Corresponding hydrogen ion concentrations were approximated from adjusted $\mathrm{pH}$ values $\left(\mathrm{pH}_{\mathrm{adj}}\right)$, Fig. 2c [16]. Phenylacetylene was added portion-wise to a pre-dried solution of $\mathrm{PdI}_{2} / \mathrm{KI}$ in methanol purged continuously with $\mathrm{CO}$. Lower catalyst concentrations, compared to those reported previously [6, 9], give a solution with increased transparency. In addition, the use of pre-dissolved catalyst solutions, as opposed to solid reagents used previously, allows exact initial concentrations of $\mathrm{PdI}_{2}$ to be determined.

A steady fall in $\mathrm{pH}$ is observed upon addition of 1 molar equivalent of phenylacetylene (relative to the concentration of $\mathrm{PdI}_{2}$ ). The rate at which the $\mathrm{pH}$ falls is accelerated by addition of a second equivalent of phenylacetylene. The observed $\mathrm{pH}$ reaches a minimum 62 min after the second addition of phenylacetylene, Fig. 2b. The $\mathrm{pH}$ then steadily rises until a further aliquot of phenylacetylene is introduced. After a 10 min induction period, a sharp drop in $\mathrm{pH}$ is observed, reaching a minimum after $20 \mathrm{~min}$. The $\mathrm{pH}$ then exhibits a steady rise over a period of $600 \mathrm{~min}$ after which stable oscillations in $\mathrm{pH}$ commence. The induction period observed prior to entering the oscillatory region is considerably shorter than the 2,000 min recorded previously at similar temperatures [17]. Temkin and co-workers $[6,8]$ were able to achieve oscillations in $\mathrm{pH}$ within minutes of starting a PCPOC reaction, however they reported an experimental setup using mixed gases $\left(\mathrm{CO} / \mathrm{O}_{2}\right)$ and higher reaction temperatures $\left(40{ }^{\circ} \mathrm{C}\right)$. The behavior reported in the present study was observed at higher catalyst loadings, using pre-dried solutions and without an external supply of oxygen to recycle the catalyst.

Oscillations vary in period between 96 and 216 min, with a maximum amplitude of $1.2 \mathrm{pH}$ units. The change in the concentration of hydrogen ions within a given oscillation, $\Delta\left[\mathrm{H}^{+}\right]_{\mathrm{adj}}$, is in the range $1-5 \times 10^{-5} \mathrm{~mol} \mathrm{dm}{ }^{-3}$, with an average of $2 \times 10^{-5} \mathrm{~mol} \mathrm{dm}{ }^{-3}$ per oscillation. The time for the $\mathrm{pH}$ to fall from its maximum to minimum value within any given oscillation is in the range $22-46 \mathrm{~min}$. Previous studies have shown that the time required for $\mathrm{pH}$ to fall within an oscillation is constant at a given temperature, with the time approximately doubling with a reduction of $10^{\circ}$ [17]. This behavior indicated a pseudo-zeroth order process, in which the reaction rate is independent of reagent concentrations, e.g. these are considered to be in excess. In the case of HPLC grade methanol used in previous studies, water is present in excess whereas for the pre-dried solutions reported here this is no longer the case.

Run 2 (Fig. 3) serves to illustrate that oscillatory behavior is both repeatable and also observed under different experimental conditions. During Run 2, stable oscillations begin 70 min after addition of phenylacetylene with the peak of the first oscillation appearing $77 \mathrm{~min}$ later, a considerably shorter induction time than 
Fig. 2 Run 1: changes in $\mathrm{pH}$ upon palladium-catalyzed oxidative carbonylation of phenylacetylene operating in an oscillatory mode. a Complete reaction. b Behavior during initial stages of the reaction. Phenylacetylene $(1 \mu \mathrm{L}$, molar equivalent relative to $\left[\mathrm{PdI}_{2}\right]$ ) was added at points, 1, 2 and 3, respectively. c Oscillatory region showing changes in $\mathrm{pH}$ and corresponding $\left[\mathrm{H}^{+}\right]_{\text {adj }}$ as a function of time. Reaction volume $=17 \mathrm{~mL}$;

$\left[\mathrm{PdI}_{2}\right]=5.4 \times 10^{-4} \mathrm{M}$;

$[\mathrm{KI}]=0.08 \mathrm{M}$;

$\mathrm{CO}=10 \mathrm{~mL} \mathrm{~min}^{-1}$;

$[\mathrm{PhAc}]_{\text {total }}=1.6 \times 10^{-3} \mathrm{M}$
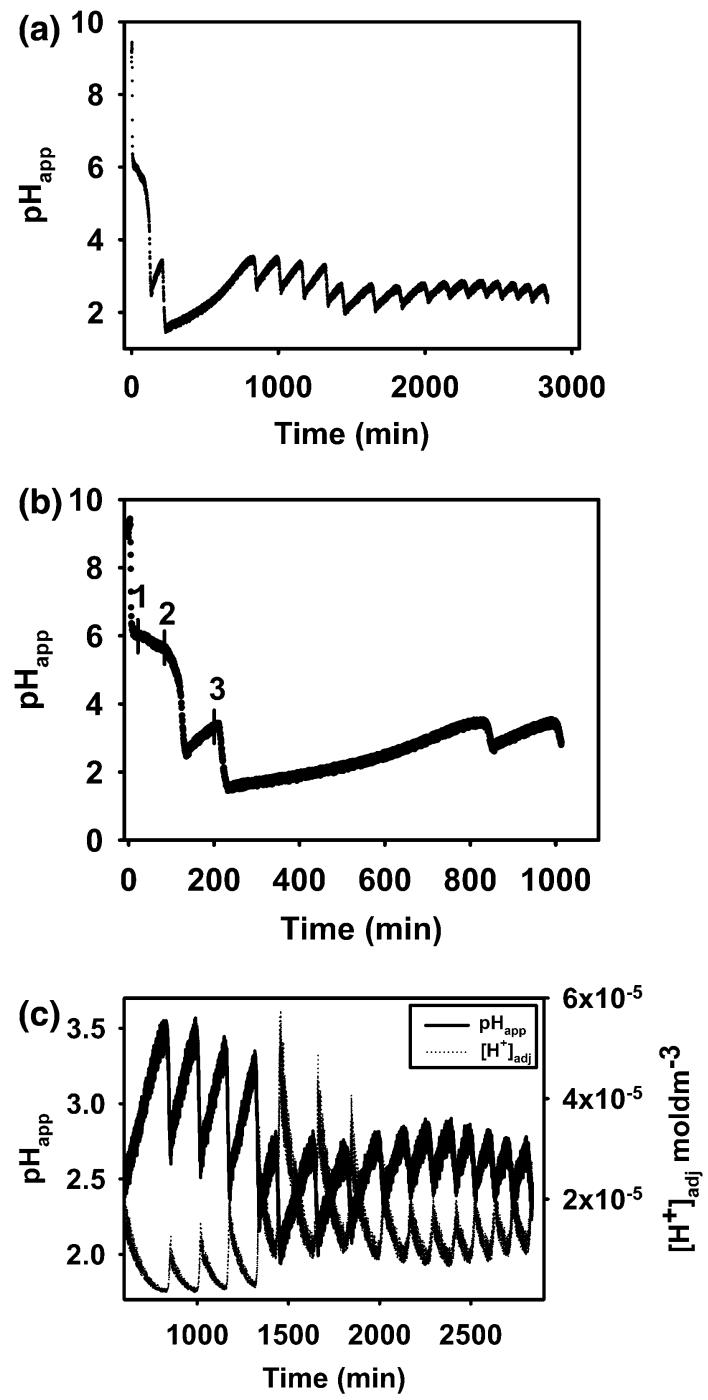

observed for Run 1. Oscillations continue in a relatively stable manner for $\sim 1,600$ min (16 cycles) after which they start to become more irregular in shape. After a period of 2,400 min oscillatory behavior becomes increasingly erratic but changes in $\mathrm{pH}$ were still observed until the reaction was terminated (4,500 $\mathrm{min})$. Oscillations have higher amplitudes and shorter periods (mean values of $0.9 \mathrm{pH}$ units and $100 \mathrm{~min}$, respectively) than for Run 1 . In addition, the time recorded for the $\mathrm{pH}$ to fall from its maximum to minimum value is also shorter, averaging 19 min. A summary of the oscillatory behavior observed in Runs 1 and 2 is given in Table 2 .

During the course of Run 2, samples of the reaction mixture were analyzed using GC-MS to determine the concentration of phenylacetylene and identify the 
Fig. 3 Run 2: changes in $\mathrm{pH}$ upon palladium-catalyzed oxidative carbonylation of phenylacetylene operating in an oscillatory mode. a Complete reaction. b Oscillatory region showing changes in $\mathrm{pH}$ and corresponding $\left[\mathrm{H}^{+}\right]_{\mathrm{adj}}$ as a function of time. Reaction volume $=90 \mathrm{~mL}$;

$\left[\mathrm{PdI}_{2}\right]=6.4 \times 10^{-4} \mathrm{M}$;

$[\mathrm{KI}]=0.150 \mathrm{M}$;

$\mathrm{CO}=15 \mathrm{~mL} \mathrm{~min}^{-1}$;

$[\mathrm{PhAc}]_{\mathrm{total}}=3.0 \times 10^{-3} \mathrm{M}$, added $15 \mathrm{~min}$ after onset of $\mathrm{CO}$ purging
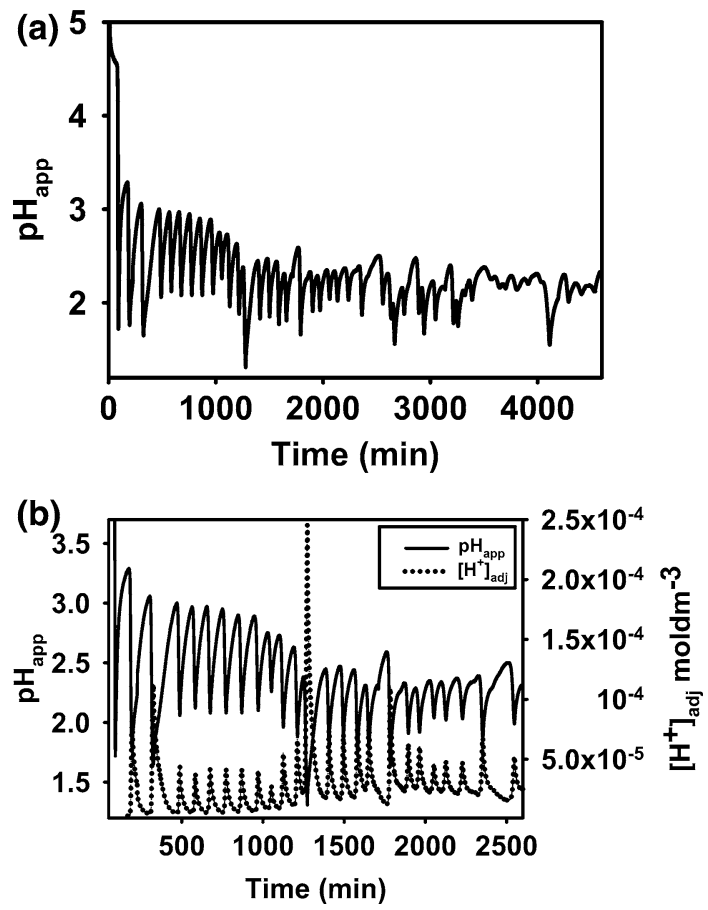

products. Conversion of phenylacetylene proceeds to $58 \%$, Fig. 4 a, forming a mixture of 3, 4, 8 and methyl iodide, Fig. 4b. Analytical standards of $\mathbf{4}$ and $\mathbf{8}$ were unavailable hence their GC-MS response and absolute concentrations were not calculated. Instead a combined (total) concentration of $\mathbf{4 / 8}$ is reported, Fig. $4 \mathrm{~b}$. The cecorded phenylacetylene conversion, in conjunction with a $\mathrm{PdI}_{2}$ loading of $21.3 \%$, suggests a catalytic rather than stoichiometric process. Pre-dried solutions of $\mathrm{PdI}_{2}$ and $\mathrm{KI}$ can thus catalyze the PCPOC reaction in the absence of an external oxygen supply.

Observation of methyl iodide within the pre-dried PCPOC system suggests a possible mechanism to account for both the limited $\mathrm{pH}$ drop upon $\mathrm{CO}$ purging and also formation of water in situ. $\mathrm{PdI}_{2}$ shows limited solubility in alcohol solvents. However, the soluble $\mathrm{PdI}_{4}{ }^{2-}$ anion is formed and stabilized in solution upon introduction of excess KI [18]. Gabriele et al. [19] have previously reported the oxidative carbonylation of a variety of alkynes using $\mathrm{PdI}_{2} / \mathrm{KI}$ and palladium iodidethiourea (tu) catalysts with a thiourea/palladium ratio of 3 or $3.5: 1$. Analogous $\mathrm{PdCl}_{2}$, $\mathrm{PdBr}_{2}$ and thiourea systems such as $\left[\mathrm{Pd}(\mathrm{tu})_{2} \mathrm{I}_{2}\right],\left[\mathrm{Pd}(\mathrm{tu})_{4}\right] \mathrm{I}_{2}$ or $\left.\left[\mathrm{Pd}(\mathrm{tu})_{4}\right]\left(\mathrm{BF}_{4}\right)_{2}\right]$ are poor or ineffective catalysts. The degree of dissociation within palladium catalysts has been highlighted as essential to their activity in carbonylation; $\mathrm{PdI}_{4}{ }^{2-}$ is likely to be at least partially dissociated in methanol solution $[18,19]$. The mechanism of phenylacetylene carbonylation, as reported by Gabriele [18], is given in Eqs. 1-4 (Scheme 1). HI is generated as a by-product accounting for the observed falls in $\mathrm{pH}$ [13]. The presence of methyl iodide suggests an equilibrium reaction between 


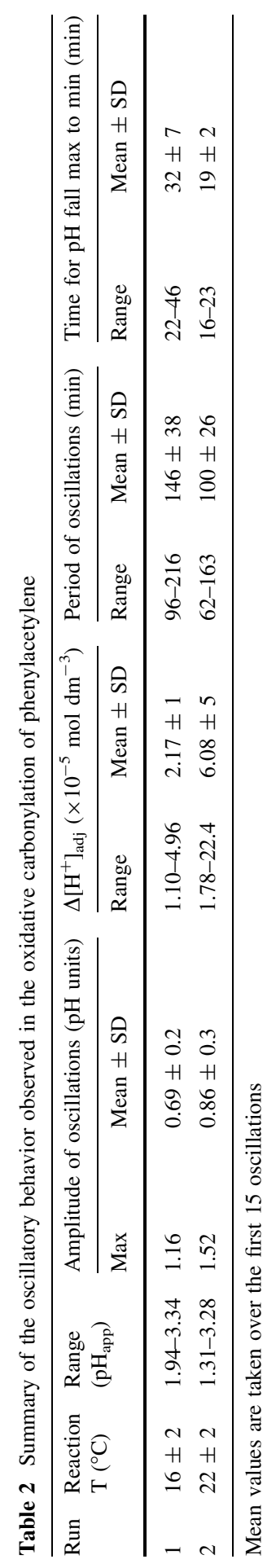


Fig. 4 Distribution of phenylacetylene and products in the PCPOC reaction.

a Oscillatory $\mathrm{pH}$ behavior with corresponding conversion of phenylacetylene.

b Concentrations of

phenylacetylene and observed products during the PCPOC reaction. Combined concentration of $\mathbf{4}$ and $\mathbf{8}$ calculated from GC-MS.

Reaction volume $=90 \mathrm{~mL}$;

$\left[\mathrm{PdI}_{2}\right]=6.4 \times 10^{-4} \mathrm{M}$;

$[\mathrm{KI}]=0.150 \mathrm{M}$;

$\mathrm{CO}=15 \mathrm{~mL} \mathrm{~min}^{-1}$;

$[\mathrm{PhAc}]_{\text {total }}=3.0 \times 10^{-3} \mathrm{M}$, added $15 \mathrm{~min}$ after onset of $\mathrm{CO}$ purging.

$[$ Naphthalene $]=0.02 \mathrm{M}$
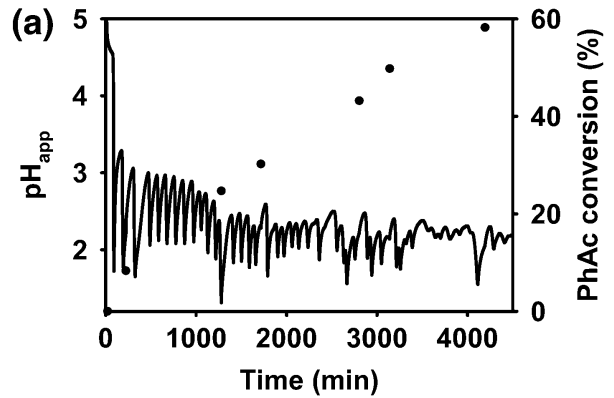

(b)

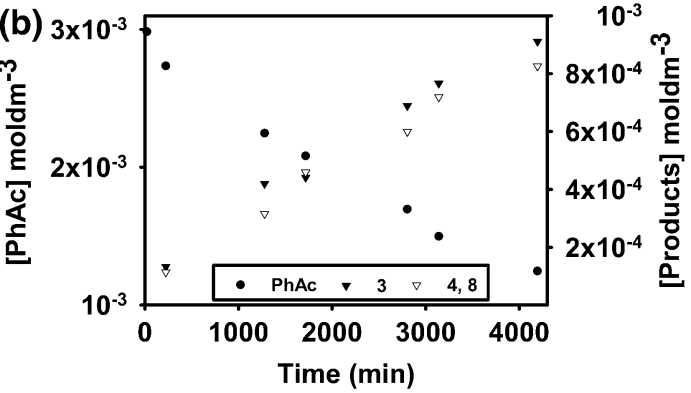

methanol and HI, generating methyl iodide and water (Eq. 5). This theory is further supported by larger $\mathrm{pH}$ drops reported when non-dried catalyst solutions are used, which are suppressed and delayed in pre-dried solutions [12]. The presence of water may initiate a cascade of reactions, including formation of $\mathrm{Pd}(\mathrm{I})$ species, which are thought to be active catalysts in the oscillatory process [7, 14]. Furthermore, unstable methyl iodide that decomposes to iodine and ethane, can account for formation of an oxidizing agent (i.e. iodine) in situ, Eq. 6 [20], and explain recorded catalyst regeneration, Eq. 7 [21].

In order to validate the mechanism proposed in Scheme 1 and probe the behavior of the catalyst system in the absence of water, a series of pre-dried catalyst solutions of $\mathrm{PdI}_{2} / \mathrm{KI}$ of differing concentration were prepared. A baseline $\mathrm{pH}$ reading was obtained for each solution over a five minute period. The exact value of apparent $\mathrm{pH}, \mathrm{pH}_{\mathrm{app}}$, varies between runs, increasing from $\mathrm{pH} 7$ to 9 with decreasing concentration of $\mathrm{PdI}_{2}$. Upon purging with carbon monoxide, a rapid drop in $\mathrm{pH}$ is observed, stabilizing after 5-10 min purging. Discussion in terms of $\mathrm{pH}$ fall is not particularly instructive given the different starting $\mathrm{pH}$ values. The change in concentration of hydrogen ions upon $\mathrm{CO}$ purging, $\Delta\left[\mathrm{H}^{+}\right]$, is calculated as $\left.\left[\mathrm{H}^{+}\right]_{\text {adj, (time } \mathrm{t}}\right)-\left[\mathrm{H}^{+}\right]_{\mathrm{adj}}$, baseline and relates to the amount of $\mathrm{HI}$ produced, Fig. 5. $\Delta\left[\mathrm{H}^{+}\right]$upon $\mathrm{CO}$ purging increases as a function of $\left[\mathrm{PdI}_{2}\right]$, suggesting that the rate of $\mathrm{HI}$ formation is a function of $\left[\mathrm{PdI}_{2}\right]$ (or more specifically the $\left[\mathrm{PdI}_{4}\right]^{2-}$ anion) which is in agreement with Eq. 1.

To examine the processes limiting the formation of hydrogen ions, samples were taken at various intervals from a $\mathrm{CO}$ purged solution of $\mathrm{PdI}_{2} / \mathrm{KI}$ and analyzed by GC-MS. The $\mathrm{pH}$ of the solution was monitored throughout and corresponding 


$$
\begin{aligned}
& \mathrm{CH}_{3} \mathrm{OH}+\mathrm{PdI}_{4}{ }^{2-}+\mathrm{CO} \leftrightarrow \mathrm{I}_{3} \mathrm{PdCOOCH}_{3}{ }^{2-}+\mathrm{HI} \\
& \mathrm{PhC} \equiv \mathrm{CH}+\mathrm{I}_{3} \mathrm{PdCOOCH}{ }^{2-} \rightarrow \mathrm{I}_{3} \mathrm{PdC}(\mathrm{H})=\mathrm{C}(\mathrm{Ph}) \mathrm{COOCH}_{3}{ }^{2-}
\end{aligned}
$$

Scheme 1 Suggested reactions associated with observed $\mathrm{pH}$ behavior and formation of methyl iodide

Fig. 5 Change in $\left[\mathrm{H}^{+}\right]_{\text {adj }}$ from baseline value $\left(\Delta\left[\mathrm{H}^{+}\right]\right)$upon purging of a pre-dried solutions of $\mathrm{PdI}_{2}$ and $\mathrm{KI}(>50 \times$ excess $)$ in methanol with $\mathrm{CO}$ $\left(10 \mathrm{~mL} \mathrm{~min}^{-1}\right)$

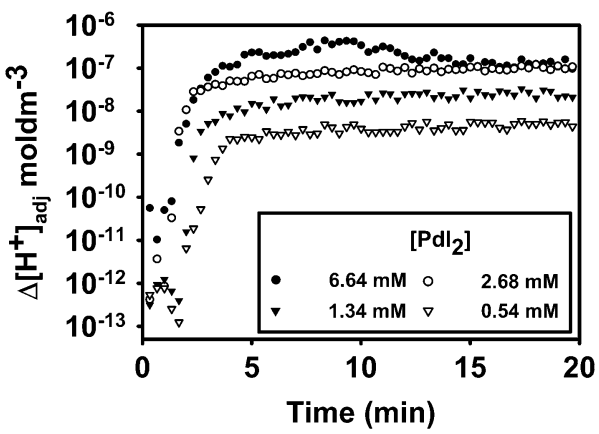

Fig. 6 Concentration of $\left[\mathrm{H}^{+}\right]_{\text {adj }}$ as a function of time for a predried solution of $\mathrm{PdI}_{2} / \mathrm{KI}$ in methanol upon $\mathrm{CO}$ purging. Molecular sieves were added to the reaction mixture $259 \mathrm{~min}$ into the experiment. $\left[\mathrm{PdI}_{2}\right]=2.55 \mathrm{mM}$; $[\mathrm{KI}]=150 \mathrm{mM}$; [Naphthalene $=0.002 \mathrm{M} ; \mathrm{CO}$ flow $=10 \mathrm{~mL} \mathrm{~min}^{-1}$

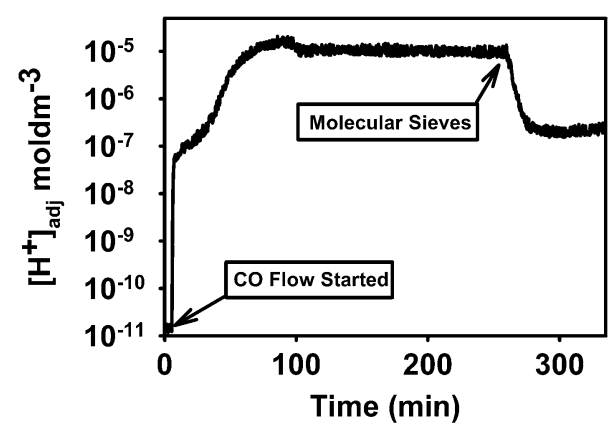

$\left[\mathrm{H}^{+}\right]_{\text {adj }}$ approximated, Fig. 6. CO purging induces a rapid increase in $\left[\mathrm{H}^{+}\right]$, which then slows and eventually stabilizes around $1 \times 10^{-5} \mathrm{M}$. Addition of molecular sieves to the reaction mixture leads to a sharp drop in $\left[\mathrm{H}^{+}\right]$.

Analysis of the CO-purged catalyst solutions by GC-MS indicates the presence of methyl iodide, the concentration of which varies during the course of the reaction. Due to the low concentrations of methyl iodide produced $\left(<1 \times 10^{-4} \mathrm{M}\right)$, its volatile nature and low GC response factor satisfactory quantification was not possible. However qualitative trends were noted. For example addition of molecular sieves leads to a large drop in $\left[\mathrm{H}^{+}\right]$and increase in $\left[\mathrm{CH}_{3} \mathrm{I}\right]$. This behavior is 
consistent with removal of water, consumption of $\mathrm{HI}$ and a shift of the equilibrium in Eq. 5 to the right. Methyl iodide production is limited by the concentration of HI in the initial stages of the reaction, Eq. 1. Synthesis of methyl iodide in methanol is known to proceed either via direct reaction of methanol with a strong acid such as HI or via an acid-catalyzed pathway in which methanol reacts with an iodide salt $[22,23]$. In the PCPOC system, KI is likely to play a part in the formation of methyl iodide, due to the large excess coupled with the relatively low concentrations of HI. The reaction is also a reversible process. Carbonylation of methyl iodide and methanol to methyl acetate is known to be catalyzed by palladium(II) salts in the presence of excess iodide. However, the reaction requires high temperatures and pressures of CO [24]. Methyl acetate was not detected so consumption of methyl iodide via such a pathway is thought to be unlikely.

\section{Conclusions}

We thus propose that the oscillatory $\mathrm{pH}$ behavior observed in pre-dried solutions of $\mathrm{PdI}_{2} / \mathrm{KI}$ is a result of the in situ formation of methyl iodide, water and iodine. Methyl iodide and water are generated reversibly in situ via reaction of HI, a byproduct of palladium-catalyzed carbonylation of methanol in the presence of KI. Iodine, formed upon decomposition of methyl iodide, provides an in situ oxidizing agent, allowing for regeneration of the $\mathrm{PdI}_{2}$ catalyst and the observed catalytic nature of this oscillatory carbonylation process. Stable oscillations of up to $1.5 \mathrm{pH}$ units are observed for several days, the onset of which can be delayed via portionwise introduction of the phenylacetylene substrate.

Acknowledgments This work was supported by Engineering and Physical Sciences Research Council (EPSRC) Grant EP H003908/1. JP would like to acknowledge Professor Allen Wright for funding her Ph.D. studies.

Open Access This article is distributed under the terms of the Creative Commons Attribution License which permits any use, distribution, and reproduction in any medium, provided the original author(s) and the source are credited.

\section{References}

1. Yoshida R (2010) Adv Mater 22:3463-3483

2. Crook CJ, Smith A, Jones RAL, Ryan AJ (2002) PCCP 4:1367-1369

3. Epstein RI, Pojman JA (1998) An introduction to nonlinear chemical dynamics: oscillations waves. Patterns and chaos. Oxford University Press, New York

4. Rábai G, Orbán M, Epstein IR (1990) Acc Chem Res 23:257-263

5. Shulykovskii GM, Temkin ON, Bikanova NV, Nirkova AN (1985) In chemical kinetics and catalysis: kinetic models of liquid phase reactions. Institute of Chemical Physics, Chernogolovka, p 112 (in Russian)

6. Malashkevich AV, Bruk LG, Temkin ON (1997) J Phys Chem A 101:9825-9827

7. Gorodskii SN, Zakharov AN, Kulik AV, Bruk LG (2001) Temkin ON Kinet Catal 42:251-263

8. Gorodskii SN, Kalenova ES, Bruk LG, Temkin ON (2003) Russ Chem Bull Int Ed 52:1534-1543 
9. Novakovic K, Grosjean C, Scott SK, Whiting A, Willis MJ, Wright AR (2007) Chem Phys Lett 435:142-147

10. Grosjean C, Novakovic K, Scott SK, Whiting A, Willis MJ, Wright AR (2008) J Mol Catal A Chem 284:33-39

11. Novakovic K, Grosjean C, Scott SK, Whiting A, Willis MJ, Wright AR (2008) PCCP 10:749-753

12. Parker J, Novakovic K (2013) Ind Eng Chem Res 52:2520-2527

13. Gabriele B, Salerno G, Costa M (2006) Top Organomet Chem 18:239-272

14. Temkin ON, Bruk LG (2003) Kinet Catal 44:601-617

15. Bradley D, Williams G, Lawton M (2010) J Org Chem 75:8351-8354

16. Porras SP, Kenndler E (2004) J Chromatogr A 1037:455-465

17. Novakovic K, Mukherjee A, Willis M, Wright AR, Scott SK (2009) PCCP 11:9044-9049

18. Gabriele B (1994) J Chem Soc Perkin Trans 1:83-87

19. Gabriele B, Salerno S, Costa M, Chiusoli GP (1995) J Organomet Chem 503:21-28

20. Harris GM, Willard JE (1954) J Am Chem Soc 76:4678-4687

21. Gabriele B, Mancuso R, Salerno G (2012) Eur J Org Chem 2012:6825-6839

22. Pickard RH, Kenyon J (1911) J Chem Soc 99:45-72

23. Stone H, Shechter H (1950) J Org Chem 15:491-495

24. Yang J, Haynes A, Maitlis PM (1999) Chem Comm 179-180 